\title{
Advanced Electrochemical Machining (ECM) for Tungsten Surface Micro-Structuring in Blanket Applications
}

N. Holstein, W. Krauss, J. Lorenz, J. Konys

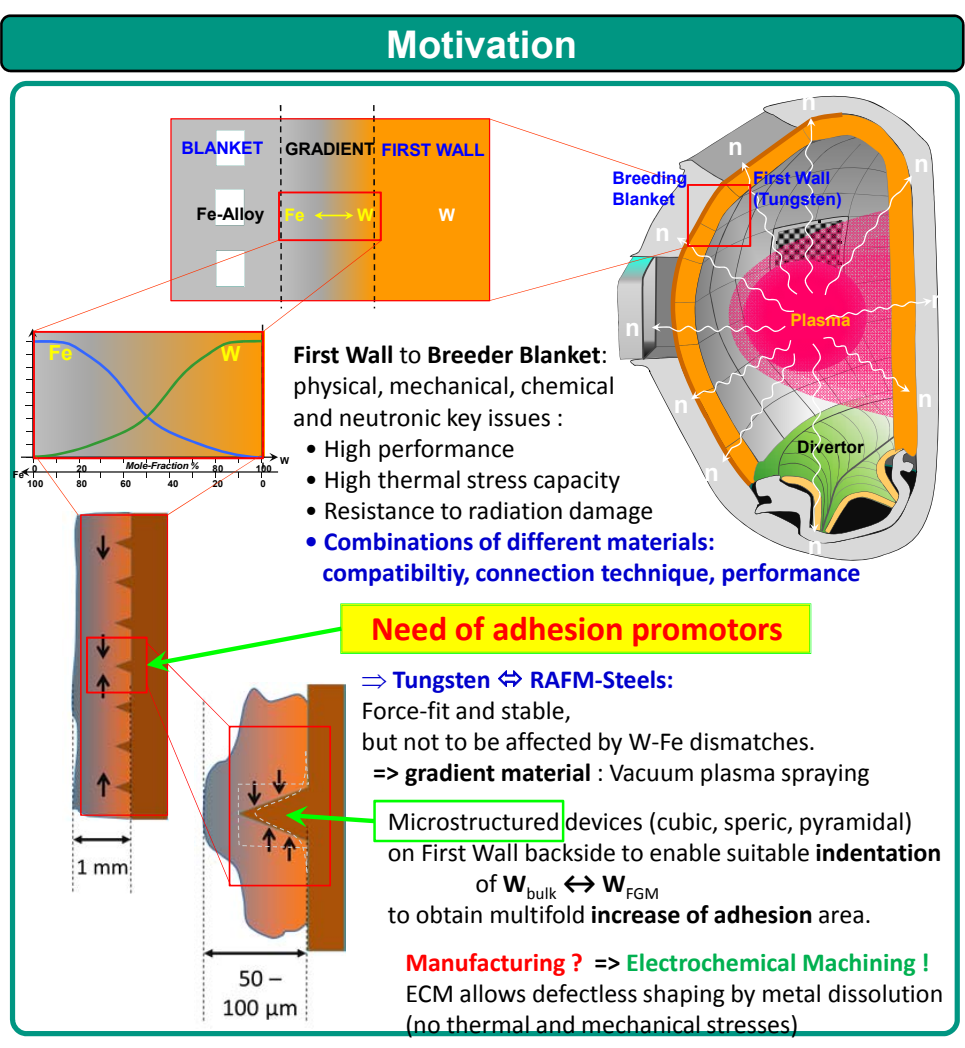

Electrochemistry of tungsten

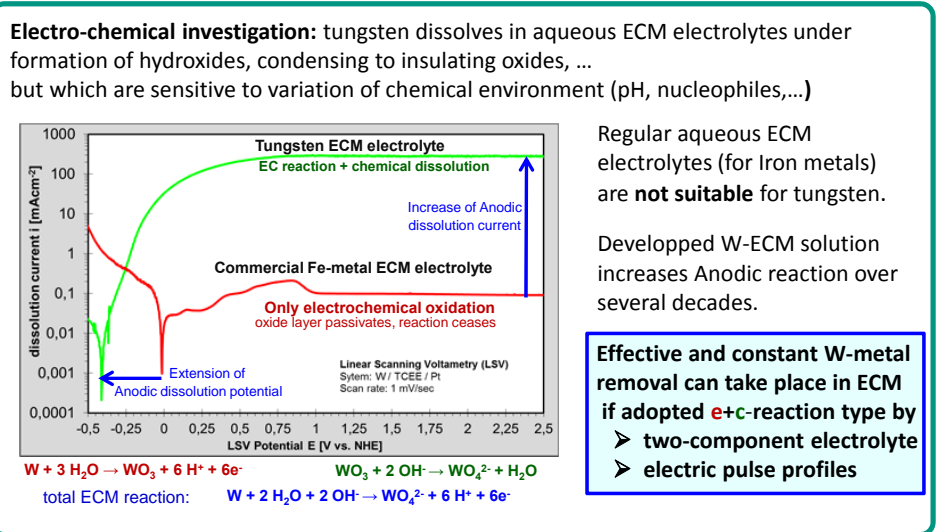

\section{ElectroChemical Machining (ECM) processes}

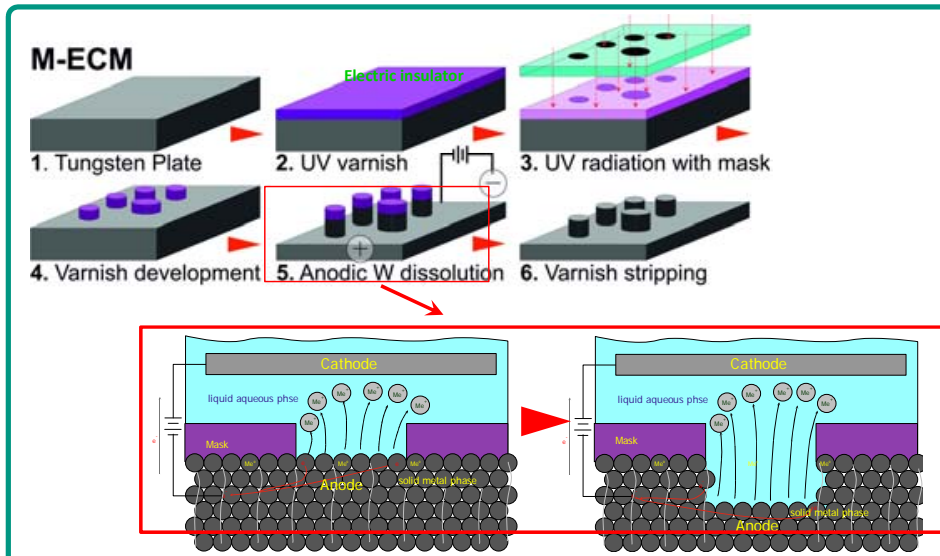

Mask-guided ECM (M-ECM): W-ablation by EC-dissolution of non-covered surface areas by a defined 2-dim resist mask $=>3$ dim shaping

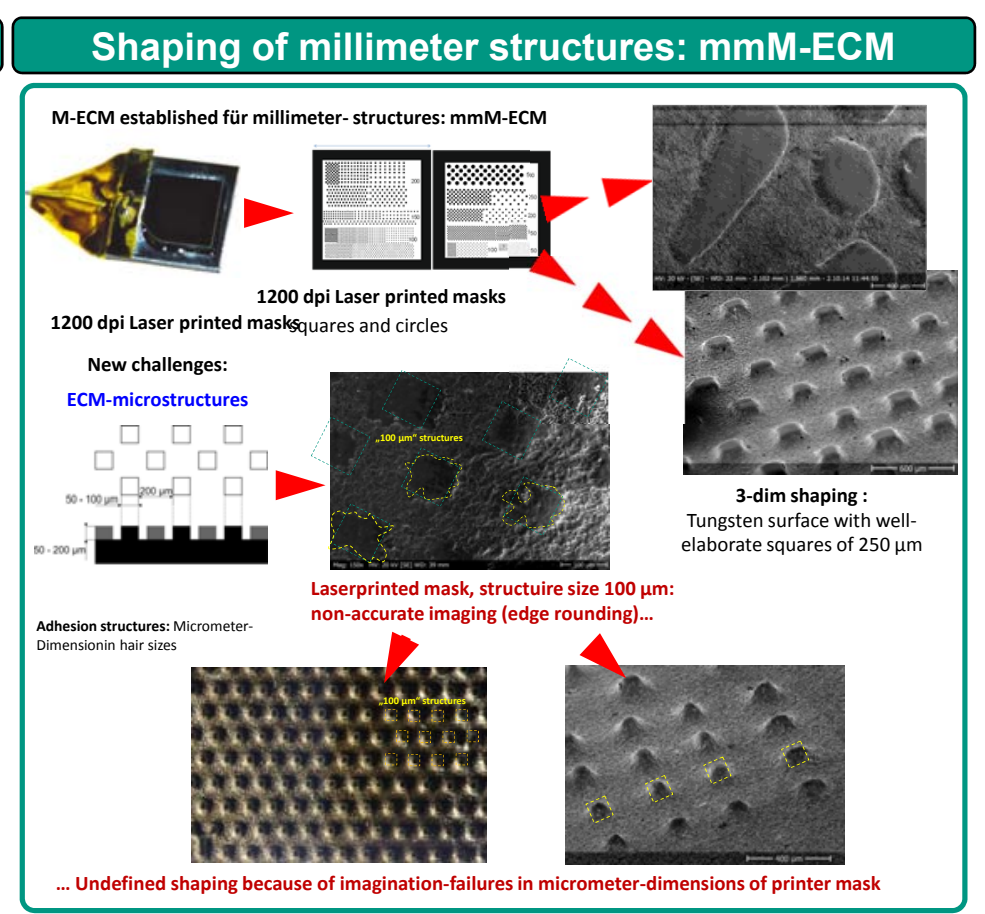

\section{Minaturization into Microstructures: $\mu \mathrm{M}$-ECM}

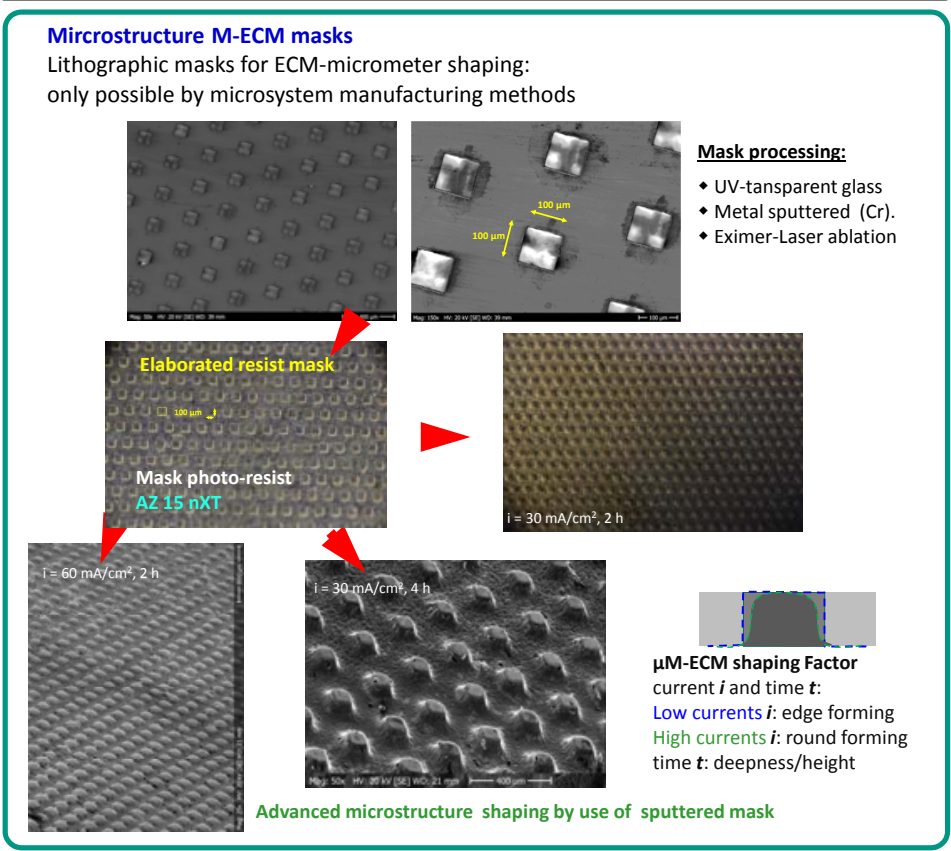

\begin{tabular}{|c|}
\hline Conclusion \\
\hline $\begin{array}{l}\text { The results of our investigations show that M-ECM can be develllopped into } \\
\text { microstructure dimensions } \\
\text { Standard two component electrolyte (TCEE) was used and conditions adopted to } \mu \mathrm{m} \text { shaping } \\
\text { W surfaces in strongly different geometrical features were successfully elaborated by } \\
\text { specifically adapted suitable parameters } \\
\text { High frequency pulse currents of } 10^{3} \mathrm{~Hz} \text { are essential } \\
\text { accuracy especially in C- ECM. } \\
1^{\text {st }} \text { Milestone: Squares of } 100 \mu \mathrm{m} \text { in required geometry imaged into tungsten bulk. } \\
\text { Further investigations: structure size } 50 \mu \mathrm{m} \text {, required edge rounding }\end{array}$ \\
\hline
\end{tabular}

\section{Acknowledgment}

These investigations were carried out at KIT, Institute of Applied Materials (IAM-AWP-KOR) in cooperation with Forschungszentrum Jülich, Institut für Energie- und Klimaforschung - Plasmaphysik (IEK-4). 